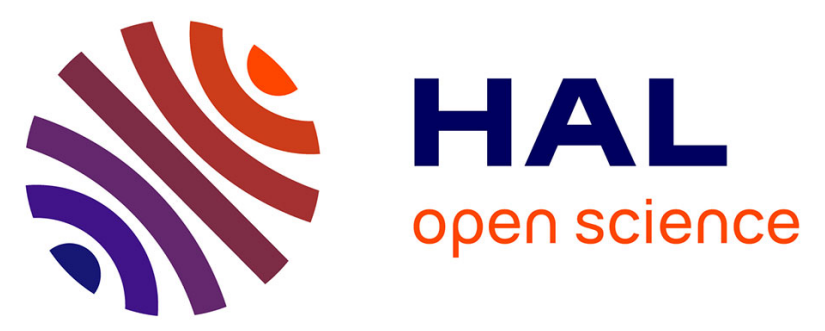

\title{
MÖSSBAUER STUDIES OF A SYNTHETIC ANALOG FOR THE ACTIVE SITE IN REDUCED RUBREDOXIN
}

\author{
V. Petrouleas, A. Simopoulos, A. Kostikas, D. Coucouvanis
}

\section{- To cite this version:}

V. Petrouleas, A. Simopoulos, A. Kostikas, D. Coucouvanis. MÖSSBAUER STUDIES OF A SYNTHETIC ANALOG FOR THE ACTIVE SITE IN REDUCED RUBREDOXIN. Journal de Physique Colloques, 1976, 37 (C6), pp.C6-159-C6-164. 10.1051/jphyscol:1976634 . jpa-00216744

HAL Id: jpa-00216744

https://hal.science/jpa-00216744

Submitted on 1 Jan 1976

HAL is a multi-disciplinary open access archive for the deposit and dissemination of scientific research documents, whether they are published or not. The documents may come from teaching and research institutions in France or abroad, or from public or private research centers.
L'archive ouverte pluridisciplinaire HAL, est destinée au dépôt et à la diffusion de documents scientifiques de niveau recherche, publiés ou non, émanant des établissements d'enseignement et de recherche français ou étrangers, des laboratoires publics ou privés. 


\title{
MÖSSBAUER STUDIES OF A SYNTHETIC ANALOG FOR THE ACTIVE SITE IN REDUCED RUBREDOXIN
}

\author{
V. PETROUleAS $(*)$, A. SIMOPOULOS, A. KOSTIKAS \\ Nuclear Research Center Demokritos, Athens, Greece \\ and \\ D. COUCOUVANiS \\ Chemistry Department, University of Iowa, USA
}

\begin{abstract}
Résumé. - La structure électronique de l'anion complexe tétrakisthiophénolate Fe(II) $\left(\mathrm{Fe}(\mathrm{SPh})_{4}\right)$ a été étudiée par effet Mössbauer dans le but de démontrer sa parenté avec le site actif de la rubredoxin réduite. La distorsion tétraédrique lève complètement la dégénérescence orbitale. La variation de l'effet quadrupolaire avec la température permet d'estimer la séparation des deux états orbitaux les plus bas (ceux provenant des états $\mathrm{E}$ de la symétrie tétraédrique); cette séparation serait voisine de $1150 \pm 100 \mathrm{~cm}^{-1}$. Les spectres magnétiques perturbés à $1,5 \mathrm{~K}$ et $4,2 \mathrm{~K}$ ont été paramétrés dans le cadre du formalisme d'un Hamiltonien de spin. Les paramètres ont été calculés au second ordre en perturbation dans un modèle du champ de ligand en tenant compte du couplage des structures fines et hyperfines. Les meilleures valeurs obtenues sont $D=10,87 \mathrm{~K}, E=2,43 \mathrm{~K}$, $g_{x}=2,12, g_{y}=2,19, g_{z}=2,01$ pour l'Hamiltonien de spin électronique et $A_{x}=1,16 \mathrm{~mm} / \mathrm{s}$, $A_{y}=0,63 \mathrm{~mm} / \mathrm{s}, A_{z}=2,09 \mathrm{~mm} / \mathrm{s}, \Delta E_{Q}=3,24 \mathrm{~mm} / \mathrm{s}, \eta=0,67$ pour le Hamiltonien nucléaire. Le très bon accord entre ces valeurs et celles obtenues par ailleurs pour $\mathrm{Rd}_{\text {red }}$ permet d'avancer que $\mathrm{Fe}(\mathrm{SPh})_{4}$ est une analogie de synthèse très satisfaisante pour le centre actif de $R \mathrm{~d}_{\text {red. }}$.
\end{abstract}

Abstract. - The electronic structure of the complex anion tetrakisthiophenolate $\mathrm{Fe}(\mathrm{II})$ $\left(\mathrm{Fe}(\mathrm{SPh})_{4}\right)$ has been studied by Mössbauer spectroscopy in order to demonstrate its validity as a synthetic analog of the active site in reduced Rubredoxin. The orbital degeneracy is completely removed due to the distorted tetrahedral geometry. From the temperature dependence of the quadrupole splitting the separation of the two low lying orbital states - those originating from the tetrahedral $\mathrm{E}$ states - is estimated at $1150 \pm 100 \mathrm{~cm}^{-1}$. Magnetically perturbed spectra at $1.5 \mathrm{~K}$ and $4.2 \mathrm{~K}$ have been parametrized with a spin Hamiltonian formalism. Spin Hamiltonian parameters have been calculated by second order perturbation theory from a ligand field model including fine and hyperfine structure coupling. The optimized spin Hamiltonian parameters are $D=10.87 \mathrm{~K}$, $E=2.43 \mathrm{~K}, g_{x}=2.12, g_{y}=2.19, g_{z}=2.01$ for the electronic spin Hamiltonian and $A_{x}=1.16 \mathrm{~mm} / \mathrm{s}, A_{y}=0.63 \mathrm{~mm} / \mathrm{s}, A_{z}=2.09 \mathrm{~mm} / \mathrm{s}, \Delta E_{Q}=-3.24 \mathrm{~mm} / \mathrm{s}, \eta=0.67$ for the nuclear spin Hamiltonian. The close agreement of these values with reported values for $\mathrm{Rd}_{\text {red }}$ constitutes strong evidence that $\mathrm{Fe}(\mathrm{SPh})_{4}$ is a satisfactory synthetic analog for the active center in $\mathrm{Rd}$ red.

1. Introduction. - The structure and electronic properties of active centers in the iron-sulfur redox proteins have been studied extensively by a variety of spectroscopic and X-ray crystallographic methods [1]. These studies have established that the basic unit of the active centers consists of iron tetrahedrally coordinated by cysteinyl sulfur atoms (S-Cys) and/or inorganic sulfide ions $\left(\mathrm{S}^{*}\right)$. It has been established that the active centers consist of linked clusters of 1,2 or 4 such tetrahedra and the number of units present in an active center has been used as a basis for classification of iron sulfur proteins. Rubredoxins (Rd), with an active site of the form $\mathrm{Fe}(\mathrm{S}-\mathrm{Cys})_{4}$, are the simplest in this class of proteins with molecular

(*) National Research Foundation Fellow. Present address : Chemical Biodynamics Lab., Lawrence Berkeley Laboratory, University of California. weights typically of the order of 6000 . Several types of rubredoxins have been isolated from bacteria in both oxidized $\left(\mathrm{Rd}_{\mathrm{ox}}\right)$ and reduced $\left(\mathrm{Rd}_{\mathrm{sed}}\right)$ form and a variety of spectroscopic methods has been used to demonstrate that the iron appears in the two redox states as $\mathrm{Fe}^{\mathrm{III}}$ and $\mathrm{Fe}^{\mathrm{II}}$ respectively [2]. Structural data obtained from Clostridium Pasteurianum $\mathbf{R d}_{\mathrm{ox}}$ at $1.5 \AA$ resolution [3] give a description of the active center as a strongly distorted tetrahedron $\mathrm{Fe}-\mathrm{S}_{4}$ with one of the Fe-S bonds unusually short $(2.05 \AA)$. Although the existence of the short bond is not yet completely certain, especially in view of recent structural studies $[4,5]$ by $\mathrm{X}$-ray absorption fine structure (EXAFS), the presence of a strong non-axial distortion is corroborated by EPR measurements in $\mathrm{Rd}_{\mathrm{ox}}$ from Clostridium pasterianum and Chloropseudomonas ethylica [6], which show a strong signal at $g=4.3$.

A great deal of information on the structure and 
electronic properties of active centers in iron-sulfur proteins has been obtained by studies of synthetic analogs where the cysteinyl residues are simulated by thiolate ligands. Successful model compounds of this type for 2-Fe and 4-Fe proteins have been synthesized and characterized in detail by Holm and co-workers [7]. The same investigators have reported recently on the synthesis and structure of the bis (o-xylyldithiolato) ferrate (III) monoanions as a structurally unconstrained model for the active site in $\mathrm{Rd}_{\mathrm{ox}}$ [8].

The preparation of a group of three mononuclear $\mathrm{Fe}(\mathrm{II})-\mathrm{S}_{4}$ tetrahedral complexes, which are candidates for simulation of the active site in $\mathrm{Rd}_{\mathrm{red}}$, has been reported recently $[9,10]$. These are the complex anions bisdithiosquarate-iron (II) $\mathrm{Fe}(\mathrm{Dts})_{2}^{2-}$ (I), dithiosquarate-bis-thiophenolato iron (II) $\mathrm{Fe}(\mathrm{Dts})$ $(\mathrm{SPh})_{2}^{2-}$ (II) and tetrakis-thiophenolato iron (II) $\mathrm{Fe}(\mathrm{SPh})_{4}^{2-}$ (III). Of these complexes only the last (III) satisfies the basic requirements for a satisfactory analog for the active site in $\mathrm{Rd}_{\text {red }}$, namely, a fully unconstrained coordination of iron-mercaptide type and reversible redox properties. The crystal and molecular structures of I and III have been determined [11]. The geometry of the Fe- $\mathrm{S}_{4}$ cluster in III is shown in figure 1 . It has the form of a distorted tetrahedron with a distortion that can be envisioned as a compression along one of the two fold axes.

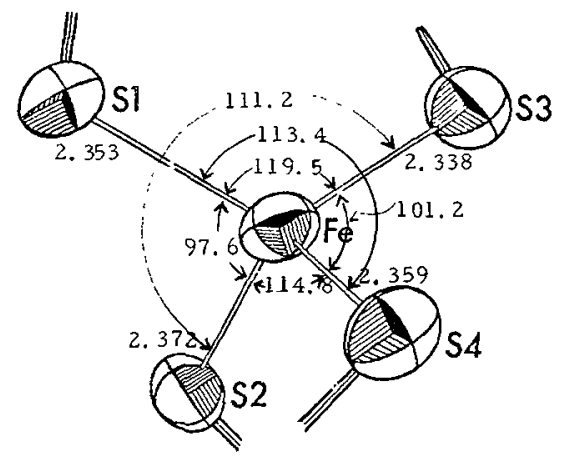

FIG. 1. - The structure of the $\mathrm{Fe}-\mathrm{S}_{4}$ core in $\mathrm{Fe}(\mathrm{SPh})_{4}^{2}$.

Preliminary Mössbauer data for the above three complex anions have been reported [12] also. Isomer shifts are similar but only III shows a quadrupole splitting, which is practically identical in magnitude and temperature dependence from $4.2 \mathrm{~K}$ to $295 \mathrm{~K}$ to that observed for $\mathrm{Rd}_{\text {red }}$. On the other hand, the differences found in zero field and magnetically perturbed spectra of the three compounds, demonstrate that Mössbauer spectroscopy is a sensitive tool for the characterization of the electronic structure of the $\mathrm{Fe}-\mathrm{S}_{4}$ units. We report in this paper an analysis of Mössbauer data for III in an applied magnetic field and a detailed comparison of these results with fine and hyperfine structure parameters reported for $\mathrm{Rd}_{\mathrm{red}}$.

2. Experimental. - Methods for preparation and characterization of $\mathrm{Fe}(\mathrm{SPh})_{4}^{2-}$ in the form of their tetraphenyl phosphonium salts have been reported elsewhere [10]. Absorbers for Mössbauer spectroscopy were prepared by grinding crystalline powder and sealing it in lucite holders. Since the compound is highly oxidizable in air, all manipulations were carried out under a dry nitrogen atmosphere. Mössbauer spectra were obtained with a conventional constant acceleration spectrometer and a ${ }^{57} \mathrm{Co}(\mathrm{Rh})$ source. Measurements were made at $1.5 \mathrm{~K}, 4.2 \mathrm{~K}$, $77 \mathrm{~K}$ and $295 \mathrm{~K}$.

3. Results and analysis. - Mössbauer spectra of $\mathrm{Fe}(\mathrm{SPh})_{4}^{2-}$ at $4.2 \mathrm{~K}$ in zero magnetic field and with applied transverse fields of 5.0 and $8.8 \mathrm{kG}$ are shown in figure 2. The zero field quadrupole doublet has

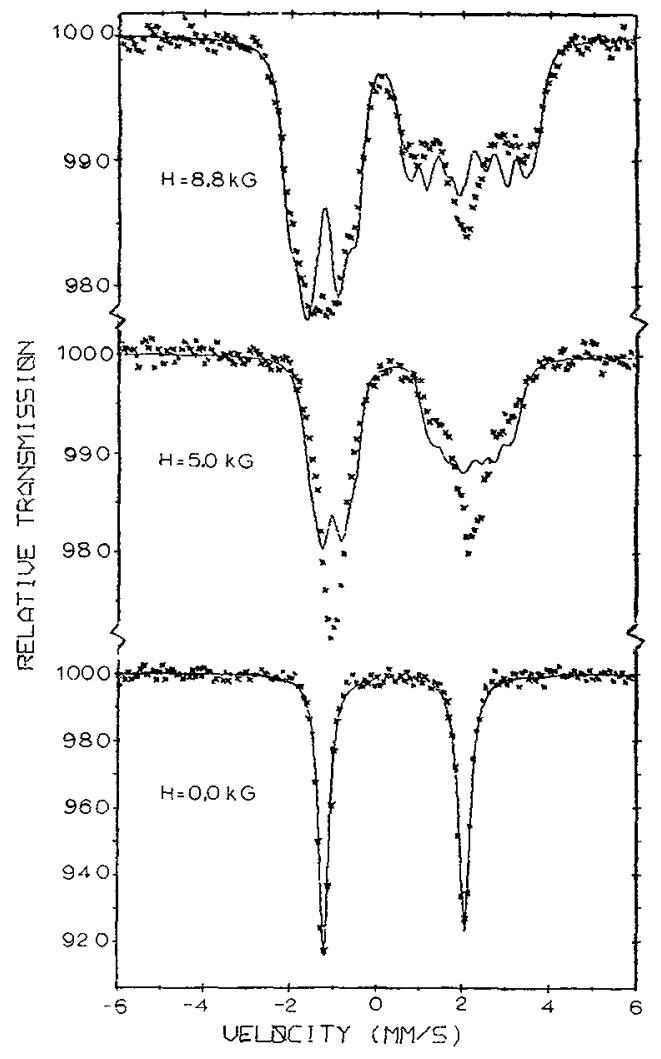

Fig. 2. - Mössbauer spectra of $\mathrm{Fe}(\mathrm{SPh})_{4}^{2-}$ at $4.2 \mathrm{~K}$ and in applied magnetic fields perpendicular to the direction of gamma rays. The solid lines have been calculated with the spin Hamiltonian parameters of table $\mathrm{I}$.

isomer shift $\delta=0.657 \mathrm{~mm} / \mathrm{s}$ and quadrupole splitting $\Delta E_{\mathrm{Q}}=3.244 \mathrm{~mm} / \mathrm{s}$ which are very close to the corresponding parameters reported for reduced rubredoxin [6, 13]. As reported earlier [12] the quadrupole splitting decreases slightly at $295 \mathrm{~K}$, also 
in agreement with the observed practically constant quadrupole splitting for $\mathrm{Rd}_{\text {red }}$. At $1.5 \mathrm{~K}$ the zero field spectrum is the same as at $4.2 \mathrm{~K}$ but the spectra in applied fields, figure 3, exhibit more defined magnetic splitting.

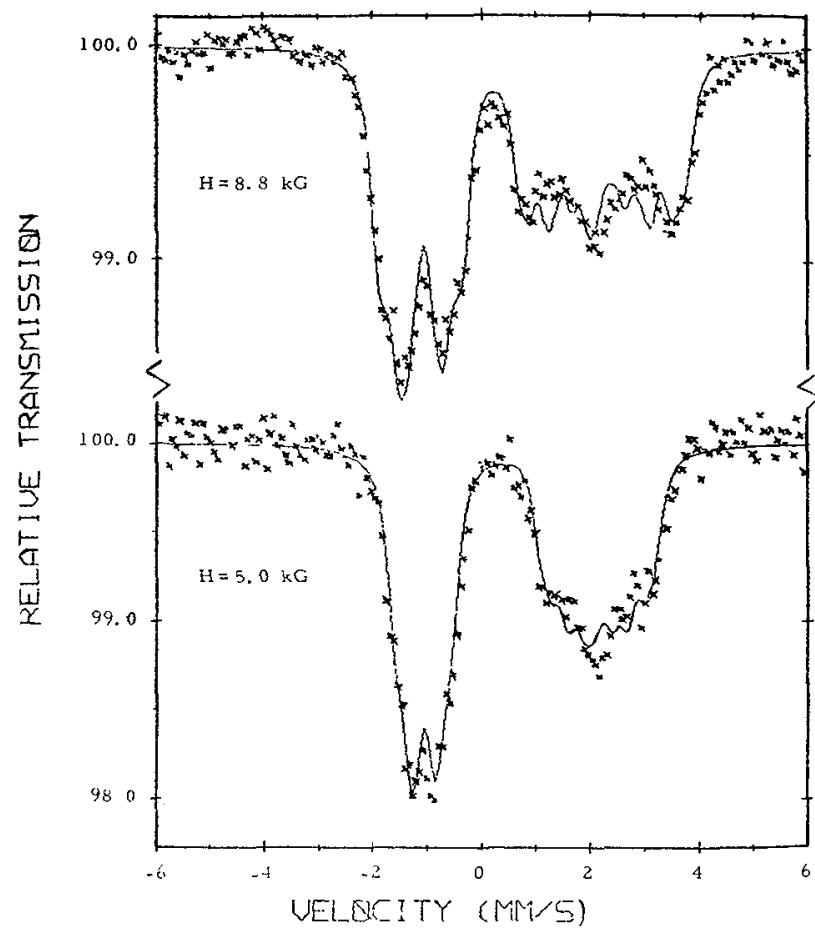

Fig. 3. - Mössbauer spectra of $\mathrm{Fe}(\mathrm{SPh})_{4}^{2-}$ at $1.5 \mathrm{~K}$ in applied magnetic fields perpendicular to the direction of gamma rays. The solid lines have been calculated with the spin Hamiltonian parameters of table $\mathbf{I}$.

As it was noted already the crystal field symmetry at the iron site is distorted tetrahedral. The magnitude of the $Q$. S. indicates that the weak crystal field case applies here. The system of the $3 \mathrm{~d}^{6}$ electrons of $\mathrm{Fe}^{2+}$ is accordingly described by a lowest ${ }^{5} \mathrm{D}$ term $(L=2, S=2)$. This term is split by the tetrahedral ligand field into a doublet $E$ and a triplet $T_{2}$ with the doublet lying lowest, figure 4. Further lowering of the symmetry to rhombic - this is the actual symmetry in the present case [11] - completely removes the degeneracy as shown in figure 4 . An estimation of the splitting, $\Delta$, of the $E$ levels may be obtained from the values of the Q. S. at 77 and $293 \mathrm{~K}$ equal to 3.241 (2) and 3.21 (2) $\mathrm{mm} / \mathrm{s}$, respectively. A calculation of the thermal average of the e. f. g., assuming two opposite contributing levels at energies 0 and $\Delta$, leads to a $\Delta$ value equal to $\sim 1150 \pm 200 \mathrm{~cm}^{-1}$. This may be compared with a value of $\Delta=850 \pm 100 \mathrm{~cm}^{-1}$ estimated from reported data for $\operatorname{Rd}_{\text {red }}[6,13]$.

The above considerations indicate that $\mathrm{Fe}(\mathrm{SPh})_{4}^{2-}$ is characterized by an orbital singlet ground state well separated from the next higher one. A pertur- bation approach is therefore well justified in the present case. This is accomplished in the analysis of the low temperature data (Figs. 2, 3) by the use of the spin Hamiltonian formalism. The latter approach has been applied extensively in Mössbauer studies of biomolecules [14] and most of the existing data are tabulated in terms of spin Hamiltonian parameters. The spin Hamiltonian appropriate to the lowest orbital singlet spin quintet electronic level of $\mathrm{Fe}(\mathrm{SPh})_{4}^{2-}$ is :

$$
\begin{aligned}
\mathscr{H}_{\mathrm{e}}=D\left[S_{z}^{2}-\frac{1}{3} S(S\right. & +1)]+E\left(S_{x}^{2}-S_{y}^{2}\right) \\
& +\beta \mathbf{S} \cdot \mathbf{g} \cdot \mathbf{H}, \quad(S=2)
\end{aligned}
$$

where $D$ and $E$ represent the familiar axial and rhombic crystal field parameters. $H_{\mathrm{e}}$ leads in general to full lifting of the spin degeneracy even in the absence of the applied field, $H$. By diagonalizing this Hamiltonian the expectation values of the spin are obtained and Mössbauer spectra may be calculated by diagonalizing the nuclear spin Hamiltonian :

$$
\begin{aligned}
\mathscr{H}_{\mathrm{N}}= & <\mathbf{S}>\cdot \mathbf{A} \cdot \mathbf{I}+\frac{e^{2} Q V_{z z}}{12} \times \\
& \times\left[3 I_{z}^{2}-\frac{15}{4}+\eta\left(I_{x}^{2}-I_{y}^{2}\right)\right]-\mathrm{g}_{n} \beta_{n} \mathbf{H} \cdot \mathbf{I}
\end{aligned}
$$

with appropriate values for the ground and excited nuclear states.

The Hamiltonians (1) and (2) have been inserted in a program which calculates polycrystalline spectra under the presence of an applied magnetic field in either the fast or the slow relaxation limit. The parameters, which can be optimized in the fitting procedure, are $D$ and $E$, the hyperfine tensor components $A_{x}, A_{y}$, $A_{z}$, the $g$ tensor components $g_{x}, g_{y}, g_{z}$ and the quadrupole splitting parameters $e^{2} Q V_{z z}$ and $\eta$. The various tensors are assumed to have coinciding principal axes systems - not necessarily in the assignment of the various axes - and the $z$ axis has been chosen along the maximum e. f. g. component. This assumption is justified by the ligand field considerations later in this section. The determination of the best values of the parameters proceeds usually by a trial and error method. This is a tedious procedure at best and leaves considerable uncertainty as to the uniqueness of the parameter set. Moreover, the spin Hamiltonian parameters are only indirectly related to the energy level scheme of the iron ion. It should be noted also that the spin Hamiltonian parameters are not mutually independent so that it is necessary to ensure their consistency.

In view of the above considerations we have used a ligand field model to calculate the parameters of the spin Hamiltonian in a second order perturbation approximation. Assuming orthorhombic crystal field symmetry the orbital wave functions are appropriately 
expressed as linear combinations of the eigenfunctions $D_{m}(m=2,1, \ldots,-2)$ of $L_{z}(L=2)$ :

$$
\begin{aligned}
& U_{5}=a D_{0}-\frac{b}{\sqrt{2}}\left(D_{-2}+D_{2}\right) \\
& U_{1}=b D_{0}+\frac{a}{\sqrt{2}}\left(D_{-2}+D_{2}\right) \\
& U_{2}=\frac{1}{\sqrt{2}}\left(D_{-1}-D_{1}\right) \\
& U_{3}=\frac{i}{\sqrt{2}}\left(D_{-1}+D_{1}\right) \\
& U_{4}=\frac{i}{\sqrt{2}}\left(D_{-2}-D_{2}\right), \quad a^{2}+b^{2}=1
\end{aligned}
$$

The $D_{m}$ are essentially spherical harmonics and the set of states (3) is isomorphous to the one electron $3 \mathrm{~d}$ wavefunctions :

$$
\begin{array}{ll}
u_{5}=a\left|3 z^{2}-r^{2}>-b\right| x^{2}-y^{2}> & \left(\mathrm{A}_{1}\right) \\
u_{1}=b\left|3 z^{2}-r^{2}>+a\right| x^{2}-y^{2}> & \left(\mathrm{A}_{1}\right) \\
u_{2}=\mid z x> & \left(\mathrm{B}_{1}\right) \\
u_{3}=\mid z y> & \left(\mathrm{B}_{2}\right) \\
u_{4}=\mid x y> & \left(\mathrm{B}_{3}\right)
\end{array}
$$

The mixing of $\left|3 z^{2}-r^{2}\right\rangle$ and $\left|x^{2}-y^{2}\right\rangle$ in $u_{5}$ and $u_{1}$ arises from the fact that they belong to the same representation of the orthorhombic group. The set (4) may be used for the calculation of e. f. g. tensor components, giving equivalent results for the case considered here, with many electron wavefunctions.

General expressions of spin Hamiltonian parameters in second order perturbation approximation are given in Abragam and Bleany [15]. The main quantities entering the calculation are of the form

$$
\frac{\left\langle n\left|L_{\mathrm{i}}\right| 0\right\rangle}{E_{n}-E_{0}} \text { or } \frac{\left\langle n\left|L_{\mathrm{i}} L_{j}\right| 0\right\rangle}{E_{n}-E_{0}}
$$

where 0 is the ground state, $n$ one of the excited states, $L_{\mathrm{i}}$ operators for components of orbital angular momentum and $E_{n}, E_{0}$ the energies of the excited and ground states respectively. To proceed further with the calculation it is necessary to establish the nature of the ground state. The spectra of figure 3 imply a negative value for the maximum component of the e. f. g. tensor and a high value of $\eta$. It may be shown that both $u_{5}$ and $u_{1}$ satisfy this requirement with proper choice of $a$ and $b$; namely $u_{5}$ gives a negative value for the maximum e. f. g. component along the $z$ axis for $0.966<a<1$ and $u_{1}$ a negative value along the $y$ axis for $\sqrt{2} / 2<a<0.966$. We shall assume in the following that the mixing is small, so that $a$ is close to 1 , in which case $u_{5}$ is the ground state.

A straightforward calculation with the expressions given in reference [15] gives the following results for the spin Hamiltonian parameters:

$$
\begin{array}{r}
g_{i}=2\left[1+\left(V_{i i}^{\prime}+2\right) \frac{\lambda k}{\Delta_{t}}\right] \\
A_{i}=-P\left[\kappa-4 \frac{\lambda k}{\Delta_{t}}-V_{i i}\left(0.071+1.893 \frac{\lambda k}{\Delta_{t}}\right)\right] \\
i=x, y, z
\end{array}
$$

$D=-1.5 V_{z z}^{\prime} \frac{\lambda^{2}}{\Delta_{t}}$

$$
\begin{aligned}
& E=\eta \frac{D}{3} \\
& \eta=-\frac{V_{x x}^{\prime}-V_{y y}^{\prime}}{V_{z z}^{\prime}} \\
& V_{x x}^{\prime}=a^{2}-2 \sqrt{3} a b-b^{2} \\
& V_{y y}^{\prime}=a^{2}+2 \sqrt{3} a b-b^{2} \\
& V_{z z}^{\prime}=-2\left(a^{2}-b^{2}\right)
\end{aligned}
$$

where $V_{i i}^{\prime}$ are the components of the e. f. g. tensor in units of $2 e<r^{-3}>/ 7, \lambda$ is the absolute value of the spin orbit coupling constant, $k$ an orbital reduction parameter, usually between 0.9 and 1 , $P=2 \mathrm{~g}_{n} \mu_{n} \beta\left\langle r^{-3}\right\rangle$ the hyperfine coupling constant and $\kappa$ the isotropic contact contribution to $A_{i}$. The energy separation $\Delta_{t}$ represents a weighted average for the energy differences between the ground state and the states $U_{2}, U_{3}, U_{4}$.

The fitting of the results of figures 2 and 3 can be effected by optimizing the parameters $\lambda, k, P, \kappa, \Delta_{t}$ and the mixing coefficient $a$. A set of parameters has been obtained first by fitting the spectrum at $1.5 \mathrm{~K}$ in a field of $8.8 \mathrm{kG}$ using as a goodness of fit criterion the usual $\chi^{2}$ sum. Initial values were estimated from free ion data: $|\lambda|=a_{\mathrm{r}}^{2} k^{2}\left|\lambda_{0}\right|$ where $\left|\lambda_{0}\right|=103 \mathrm{~cm}^{-1}$ for $\mathrm{Fe}^{2+}$ [16] and $a_{\mathrm{r}}^{2}$ a reduction parameter accounting for radial expansion ; $P=a_{\mathrm{r}}^{2} P_{0}$, where $P_{0}=-3.87 \mathrm{~mm} / \mathrm{s}$ calculated for the excited state with $\left\langle r^{-3}\right\rangle_{0}=4.57$; and $\kappa=0.48$. The values obtained from the fitting procedure are listed in table $\mathrm{I}$. The $x^{2}$ value for this set is 1.3 . The error limits given in table I should be considered preliminary since the search in parameter space has not been exhaustive, but they roughly represent the limits in which the $\chi^{2}$ value is equal to 2 . The fitting is most sensitive to the values of $\Delta_{t}, P$ and the mixing coefficient $a$. The spin Hamiltonian parameters derived using equation (5) are listed also in table $I$. The validity of the spin hamiltonian parameters in table $I$ is further justified by fitting the spectrum for $H=5.0 \mathrm{kG}$ (Fig. 3).

The fitting of the spectra at $1.5 \mathrm{~K}$ (Fig. 3) is independent of the rate of electronic relaxation. This is due to substantial thermal occupation of only the 
TABLE 1

Electronic Structure Parameters and Derived Spin Hamiltonian Parameters for $\mathrm{Fe}(\mathrm{SPh})_{4}$

\begin{tabular}{lrlc}
\multicolumn{2}{c}{$\begin{array}{c}\text { Electronic } \\
\text { Parameters }\end{array}$} & \multicolumn{2}{c}{$\begin{array}{c}\text { Spin Hamiltonian } \\
\text { Parameters }\end{array}$} \\
$\lambda\left(\mathrm{cm}^{-1}\right)$ & $90 \pm 10$ & $g_{x}$ & 2.12 \\
$\Delta_{\mathrm{t}}\left(\mathrm{cm}^{-1}\right)$ & $\sim 3000$ & $g_{y}$ & 2.19 \\
$k$ & $\sim 0.9$ & $g_{z}$ & 2.01 \\
$P .(\mathrm{mm} / \mathrm{s})$ & $-3.5 \pm 0.2$ & $A_{x}^{(a)}(\mathrm{mm} / \mathrm{s})$ & 1.16 \\
$\mathrm{~K}$ & 0.48 & $A_{y}^{(a)}(\mathrm{mm} / \mathrm{s})$ & 0.63 \\
$a$ & $0.933 \pm 0.005$ & $A_{z}^{(a)}(\mathrm{mm} / \mathrm{s})$ & 2.09 \\
& & $D(\mathrm{~K})$ & 10.87 \\
& & $E(\mathrm{~K})$ & 2.43 \\
& & $\Delta E_{\mathrm{Q}}^{(c)}(\mathrm{mm} / \mathrm{s})$ & -3.24 \\
& & $\eta^{(c)}$ & 0.67 \\
& & $\delta^{(b)}(\mathrm{mm} / \mathrm{s})$ & $0.657 \pm 0.002$
\end{tabular}

(a) $A_{i}$ values for the excited nuclear state.

(b) Isomer shift at $4.2 \mathrm{~K}$ relative to iron at room temperature. (c) At $T \leqslant 4.2 \mathrm{~K}$.

ground spin hamiltonian eigenstate at this temperature. The parameters of table I are therefore independent of any relaxation effects and have been used for the simulation of the spectra at $4.2 \mathrm{~K}$ in the fast or the slow relaxation limit. Only the slow relaxation calculation has given reasonable fitting to the spectra as shown in figure 2 . The discrepancies, which appear in the line intensities, are most probably due to relaxation effects at intermediate rates.

4. Discussion. - The results of the previous section give a detailed characterization of the electronic structure of $\mathrm{Fe}(\mathrm{SPh})_{4}^{2-}$ anion, which may be used in establishing its validity as a model for the active site in reduced rubredoxin. As noted already the values of the isomer shift and quadrupole splitting at $4.2 \mathrm{~K}$ are in close agreement with those reported by Rao et al. [6] and Debrunner and Schulz [13]. The small variation of the quadrupole splitting found in $\mathrm{Rd}_{\text {red }}$ is also reproduced in $\mathrm{Fe}(\mathrm{SPh})_{4}^{2-}$ implying similar splittings of the lowest two orbital states in the two systems. The significance of this agreement is demonstrated by the marked differences in the values and temperature dependence of the quadrupole splitting in the other two tetrahedral $\mathrm{Fe}_{4} \mathrm{~S}_{4}$ anions, $\mathrm{Fe}(\mathrm{dts})_{2}^{2-}$ and $\mathrm{Fe}(\mathrm{dts}) \mathrm{Ph}^{2-}$ reported earlier [12]. In fact, structure data [11] for $\mathrm{Fe}(\mathrm{dts})_{2}^{2-}$ show that the $\mathrm{Fe}-\mathrm{S}_{4}$ core has a geometry slightly different from $\mathrm{Fe}(\mathrm{SPh})_{4}^{2-}$ but the quadrupole splitting varies from $4.006 \mathrm{~mm} / \mathrm{s}$ at $4.2 \mathrm{~K}$ to $2.75 \mathrm{~mm} / \mathrm{s}$ at room temperature.

Further evidence for the similarity of the electronic structure of $\mathrm{Fe}(\mathrm{SPh})_{4}^{2-}$ and the active site in $\mathrm{Rd}_{\text {red }}$ can be obtained by a comparison of crystal field and magnetic hyperfine structure parameters. Magnetically perturbed Mössbauer data for $\mathrm{Rd}_{\mathrm{red}}$ have been reported by Rao et al. [6] who have suggested that the observation of well defined magnetic hyperfine structure implies the presence of strong anisotropy, and estimated a saturation value of about $-200 \mathrm{kG}$ for the internal field in the direction perpendicular to the $z$ axis of the electronic Hamiltonian. More detailed results and an analysis in terms of spin Hamiltonian parameters for $\mathrm{Rd}_{\mathrm{red}}$ from Clostridium pasteurianum has been reported recently by Debrunner and Schulz [13]. Their results agree closely with the spin Hamiltonian parameters for $\mathrm{Fe}(\mathrm{SPh})_{4}$ given in table $\mathrm{I}$. The most interesting common feature is the moderately large value of $D \simeq 11 \mathrm{~cm}^{-1}$ and the strong rhombic distortion $E / D \sim 0.25$.

It is easily seen that under these conditions the five fold spin degeneracy of the ground state is completely removed and at zero field all five states have zero expectation value of the spin. An applied magnetic field induces polarization with markedly different anisotropy properties for the five states. At $1.5 \mathrm{~K}$ only the lowest state is occupied and the combined effects of solid angle and rhombic anisotropy give a spectrum dominated by $\left\langle S_{y}\right\rangle$. With a saturation value $\left\langle S_{y}\right\rangle=-2$ and the value of $A_{y}$ from table I we find an internal field of $-186 \mathrm{kG}$ which may be compared with that of Rao et al. [6]. It must be pointed out, however, that the use of an effective field in this case is an oversimplification and that a proper comparison of the electronic structures should include all the parameters of the spin Hamiltonian.

After having established the similarity of the electronic structures of $\mathrm{Fe}(\mathrm{SPh})_{4}^{2-}$ and the active center in $R_{d_{r e d}}$ it is interesting to examine the parameters of the fine and hyperfine structure, which have served as basis for the calculation of spin Hamiltonian parameters. It is noted first that the spin orbit coupling constant is reduced by about $10 \%$ relative to the

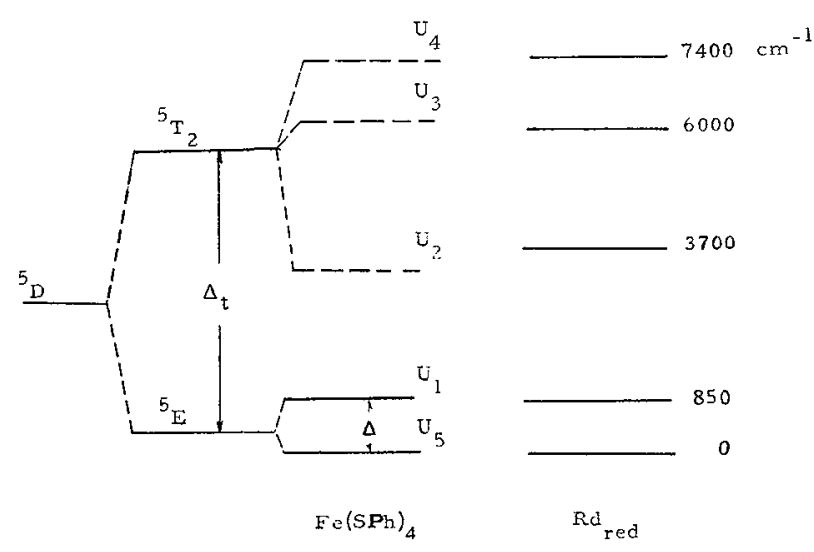

FIG. 4. - Schematic representation of the splitting of the $\mathrm{Fe}^{2+}$ free ion state $5 \mathrm{D}$ in distorted tetrahedral coordination as in $\mathrm{Fe}(\mathrm{SPh})_{4}$. The energy level scheme for $\mathbf{R d}_{\mathrm{red}}$ constructed from optical and Mössbauer data (reference 2) is shown on the right hand side. 
free ion implying small covalency effects. The same conclusion may be drawn from the value of $P$. Of more interest is the value of $\Delta_{t}$ which gives approximately the splitting of the ${ }^{5} \mathrm{E}$ and ${ }^{5} \mathrm{~T}_{2}$ states. Optical data for reduced rubredoxin give a value for this parameter of about $5000 \mathrm{~cm}^{-1}$ [17]. An energy level diagram including the splitting due to rhombic distortion has been given by Eaton and Lovenberg and is shown in figure 4. The lowest state of the ${ }^{5} \mathrm{~T}_{2}$ group is at $3700 \mathrm{~cm}^{-1}$ higher than the ground state, which is at the upper limit of the value for $\mathrm{Fe}(\mathrm{SPh})_{4}^{2-}$. Further discussion of these results, however, must await the confirmation of the uniqueness of the parameters derived for $\mathrm{Fe}(\mathrm{SPh})_{4}^{2-}$ by measurements at higher temperatures and magnetic fields.

The main conclusion, that may be drawn from this study, is that the electronic structure of the active site in $R_{\text {red }}$ can be accurately reproduced by the anion $\mathrm{Fe}(\mathrm{SPh})_{4}^{2-}$ where $\mathrm{Fe}^{2+}$ is coordinated by unconstrained mercaptide ligands simulating the cysteine residues in rubredoxin. This indicates that it may not be necessary to invoque an entatic state hypothesis [18] for the explanation of the geometry and electronic properties of the active center and in conjunction with the EXAFS results casts considerable doubt about the existence of the short bond in rubredoxin.

\section{References}

[1] Iron Sulfur Proteins, Lovenberg, W. Ed. (Academic Press, New York) 1973.

[2] Eaton, N. A. and Lovenberg, W., in Iron Sulfur Proteins, W. Lovenberg Ed. (Academic Press, New York) 1973, Chapter 3. Vol. II.

[3] Jensen, L. H., Ann. Rev. Biochem. 43 (1974) 461.

[4] Shulman, R. G., Eisenberger, P., Blumberg, W. E. and Stombaugh, N. A., Proc. Nat. Acad. Sci. USA 72 (1975) 4003.

[5] Sayers, D. E., Stern, E. A., Herriot, J. R., J. Chem. Phys. 64 (1976) 427.

[6] Rao, K. K., Evans, M. C. W., Cammack, R., Hall, D. O., Thomson, C. L., JACKson, P. J., Johnson, C. E., Biochem. J. 129 (1972) 1063.

[7] Holm, R. H., Endeavour 34 (1975) 38.

[8] Lane, R. W., Ibers, James, A., Frankel, R. B. and Holm, R. H., Proc. Nat. Acad. Sci. USA 72 (1975) 2868.

[9] Coucouvanis, D., Holah, D. G. and Hollander, F. J., Inorg. Chem. 14 (1975) 2657.

[10] Holah, D. G. and Coucouvanis, D., J. Amer. Chem. Soc. 97 (1975) 6917.
[11] Coucouvanis, D., Swenson, D., Baenzinger, N. C., Holah, D. G., Kostikas, A., Simopoulos, A. and Petrouleas, V., J. Am. Chem. Soc. 98 (1976) 5721.

[12] Kostikas, A., Petrouleas, V., Simopoulos, A., CoucouvaNIS, D. and Holah, D. G., Chem. Phys. Lett. 38 (1976) 582.

[13] (a) Debrunner, P. and Schulz, C., Moessbauer Effect Methodology, Gruverman, I. J. and Seidel, C. W. ed. (Plenum Press, New York) 1976, vol. 10. (b) Schulz, C. and Debrunner, P., J. Physique Colloq. 37 (1976) C 6.

[14] Münck, E. and Champion, P. M., J. Phys. C 6 (1975) 33.

[15] Abragam, A. and Bleaney, B., Electron Paramagnetic Resonance of Transition Ions (Oxford University Press) 1970, p. 749.

[16] Abragam, A. and Bleaney, B., ibid. p. 399.

[17] Eaton, W. A. and Lovenberg, W., J. Am. Chem. Soc. 92 (1970) 7195

[18] Vallee, B. L. and Williams, R. J. P., Proc. Nat. Acad. Sci. USA 59 (1968) 498. 